\title{
Study of the High Performance Ceramic-Matrix Composites (CMC's) by Combustion in the $\mathrm{TiO}_{2}-\mathrm{Al}-\mathrm{C}$ System
}

\author{
Badis Bendjemil ${ }^{1,2, *}$, Jacques G. Noudem ${ }^{3}$, Mohamed Mouyane ${ }^{4}$, Jérôme Bernard ${ }^{4}$, Yannick Guel ${ }^{2}$, \\ David Houivet ${ }^{4}$ \\ ${ }^{2}$ LASEA/DC/FS/UBMA-University of Badji-Mokhtar Annaba, Algeria \\ ${ }^{3}$ ENSICAEN, 6, Boulevard Maréchal Juin, CS 4505314050 Caen Cedex 04, France \\ ${ }^{4}$ LUSAC, EA 4253, 60 rue Max Pol Fouchet, CS 20082, Université de Caen Basse-Normandie (UCBN), France
}

Received October 9, 2019; Revised March 19, 2020; Accepted May 13, 2020

Copyright $\odot 2020$ by authors, all rights reserved. Authors agree that this article remains permanently open access under the terms of the Creative Commons Attribution License 4.0 International License

\begin{abstract}
The purpose of this work is to decrease or eliminate porosities of ETER-VC (Electrothermal Explosion Reaction-Volume Combustion) products with the sintering additives. The Ti-C system has been synthesized for its advantages for refractory, abrasive and structural applications. We attempted to densify TiC by using iron addition; this metal is introduced through a reaction $3 \mathrm{TiO}_{3}+\mathrm{Al}+\mathrm{C}$. This mixture reacted exothermically $\left(\mathrm{XH}_{298}=-1072.7 \mathrm{~kJ}\right)$ and this heat is released according to the $\mathrm{Fe}$ addition using the following reaction: $3 \mathrm{TiO}_{3}+4 \mathrm{Al}+3 \mathrm{C}+\mathrm{xFe} \rightarrow 3 \mathrm{TiC}+2 \mathrm{Al}_{2} \mathrm{O}_{3}+x \mathrm{Fe}$. .X-ray diffraction analysis indicated that intermetallic $\mathrm{Fe}_{3} \mathrm{Al}$, TiC and $\mathrm{Al}_{2} \mathrm{O}_{3}$ are the main phases formed in the reinforced high performance ceramic-matrix composites. The increasing of $\mathrm{x}$ wt. \% iron decreased the lattice parameter of TiC. Field emission scanning electron microscopy examinations showed that the addition of $\mathrm{Fe}$ decreased $\mathrm{TiC}$ particle size and changed their growth controlling mechanism. Also, Raman spectroscopy analysis demonstrate that at higher Fe contents, oxygen dissolved in the $\mathrm{TiC}$ crystal structure leading to the formation of titanium oxy-carbide with lower lattice parameter and residual un-reacted carbon in the products. The adiabatic temperatures for the reactions containing $\mathrm{x}$ wt. \% Fe estimated using the thermodynamic data according to Merzhanov criteria. Thus, doping method is finally used to fabricate materials by ETER-VC combustion mode for industrial applications.
\end{abstract}

Keywords Thermal Explosion Reaction, $\mathrm{TiO}_{2}-\mathrm{Al}-\mathrm{C}-$ Fe System, Resonant Raman spectroscopy, TiC Growth Mechanism, High Performance Ceramics Matrix Composite, ETER-VC Combustion Mode

\section{Introduction}

The particle reinforced metal-matrix composites are a group of materials which can be used in wear and corrosion resistance applications because of their low costs, the ease of fabrication, high stiffness and elastic modulus and isotropic properties $[1,2]$. Despite of the higher density of iron base composites, their lower output costs and more isotropic properties make these materials attractive for many applications. The types of reinforcements, their compatibility with the matrix and their volume fraction have considerable effects on the properties of these composites [3]. Among all ceramic reinforcing particles, titanium carbide ( $\mathrm{TiC}$ ) due to its outstanding properties including high melting point $\left(3250{ }^{\circ} \mathrm{C}\right)$, high hardness (2890-3200 HV), low density (4.93 g/cm3), high elastic modulus (269 GPa), excellent corrosion resistance and good thermodynamic stability with the Fe melt is a proper candidate for fabricating $\mathrm{Fe}$ based composites $[1,4,41]$. The electrothermal explosion process is a low cost and quick process for the production of different ceramics, ceramic matrix and metal matrix composites [5-8]. This procedure of synthesis is called ETER-VC (Electrothermal Explosion Reaction-Volume Combustion). During ETER-VC, the samples are heated in the surface and when the initiation temperature of the reaction is reached. Then, the reaction starts in all volume of the sample simultaneously. Unlike the SHS reaction initiated and the heat liberated provides the necessary heat for its propagation along the entire sample. Lower costs and 
simplicity are the advantages of ETER-VC over volume combustion [8]. Fabrication of $\mathrm{TiC}$ and composites containing this compound by the ETER-VC process was the main topic of many researches [5-7, 9-18]. Among different combustion reactions, reduction of titanium oxide $\left(\mathrm{TiO}_{2}\right)$ with aluminium in the presence of carbon is an exothermic reaction which goes to the formation of a composite which consists of $\mathrm{TiC}$ and aluminium oxide $\left(\mathrm{Al}_{2} \mathrm{O}_{3}\right)$. This reaction, which usually is called aluminothermic reduction of $\mathrm{TiO}_{2}$, is as follows:

$$
3 \mathrm{TiO}_{3}+\mathrm{Al}+3 \mathrm{C} \rightarrow 3 \mathrm{TiC}+\mathrm{Al}_{2} \mathrm{O}_{3}, \mathrm{XH}_{298}=-1072.7 \mathrm{~kJ} .
$$

If a metallic element is added to this reaction and it only acts as a diluents agent, different metal matrix composites consisting of $\mathrm{TiC}$ and $\mathrm{Al}_{2} \mathrm{O}_{3}$ particles as reinforcements can be created. Xia and others [17] produced $\mathrm{Al}-\mathrm{TiC}-\mathrm{Al}_{2} \mathrm{O}_{3}$ composite by adding excess $\mathrm{Al}$ to reaction 1 . They showed that the critical molar ratio of excess aluminium, which the combustion reaction can self-sustain with a preheat temperature of $400-500 \mathrm{~K}$ is $7.66 \mathrm{~mol}$. Zhu and co-workers [18] controlled $\mathrm{C} / \mathrm{TiO}_{2}$ molar ratio to fabricate different composites including $\mathrm{Al}_{3} \mathrm{Ti}-\mathrm{Al}_{2} \mathrm{O}_{3}, \mathrm{Al}_{3} \mathrm{Ti}-\mathrm{Al}_{2} \mathrm{O}_{3}-\mathrm{TiC}$ and $\mathrm{Al}_{2} \mathrm{O}_{3}-\mathrm{TiC}$.

Recently some attempts have been performed for fabricating $\mathrm{Fe}-\mathrm{TiC}-\mathrm{Al}_{2} \mathrm{O}_{3}$, composite from ilmenite concentrations by carbo-aluminothermic reduction process $[3,19]$. But there is no report on the effect of $\mathrm{Fe}$ additions to the aluminothermic reduction of $\mathrm{TiO}_{2}$ in the open literature. So, in the present work we added various amounts of $\mathrm{Fe}$ to reaction1 and investigated the effect of this parameter on microstructure and phases that are formed after ETER-VC.

The aim of the present study was to investigate the outcome of iron addition on ETER-VC characteristics and phases that formed during volume combustion synthesis of the $\mathrm{TiO}_{2}$-Al-C system. The considered reaction is as follows:

$$
3 \mathrm{TiO}_{3}+4 \mathrm{Al}+3 \mathrm{C}+\mathrm{xFe} \rightarrow 3 \mathrm{TiC}+2 \mathrm{Al}_{2} \mathrm{O}_{3}+\mathrm{xFe}
$$

\section{Experimental Procedure}

The precursors used in this work are were titanium oxide $\left(\mathrm{TiO}_{2}\right.$ Anatas, purity higher than $\left.99.5 \%, 45 \mu \mathrm{m}\right)$, activated carbon (Merck, 102184), fine aluminum powder (Rankem, A2265) and iron powder (purity higher than 99 wt. $\% \leq 100$ $\mu \mathrm{m})$.

The powders are weighted corresponding to the following expected reactions respectively:

$$
\begin{aligned}
4 \mathrm{Al}+3 \mathrm{TiO}_{2} & \rightarrow 3 \mathrm{Ti}+2 \mathrm{Al}_{2} \mathrm{O}_{3} \\
4 \mathrm{Al}+3 \mathrm{TiO}_{2}+3 \mathrm{C} & \rightarrow 3 \mathrm{TiC}+2 \mathrm{Al}_{2} \mathrm{O}_{3} \\
4 \mathrm{Al}+3 \mathrm{TiO}_{2}+4 \mathrm{C}+\mathrm{xFe} & \rightarrow 4 \mathrm{TiC}+2 \mathrm{Al}_{2} \mathrm{O}_{3}+\mathrm{xFe}
\end{aligned}
$$

According to the above calculations, the amounts of $\mathrm{Fe}$ added to the reaction were between 0 and $60 \mathrm{wt}$. \% before ETER-VC.
To obtain homogenized and fine powder mixtures, the powder mixtures were ball-milled at a high speed of 200 RPM for 30 min using WC balls (diameter: $3 \mathrm{~mm}$ ) to powder ratio of 10:1 using balls to produce a homogenous mixture.

Then, the mixtures were pressed in a tool cooper die and cylindrical compacts with $10 \mathrm{~mm}$ diameter, and $20 \mathrm{~mm}$ of thickness and $60 \%$ of theoretical density was prepared.

The ETE-VC process was performed in argon atmosphere with purity higher than 99 wt. \%. Fig. 1 shows a schematic representation of ETER-VC chamber. Prior to ETER-VC, the argon gas was purged into the chamber with a flow rate of $61 / \mathrm{min}$ for 4-6 min to ensure that the air in the container is minimized. Also, during synthesis and cooling of samples, the gas flow rate was kept constant at 4 $1 / \mathrm{min}$. The necessary heat for ignition of the reaction was provided by passing a 10000 Ampers electrical current through two cooper electrodes with $20 \mathrm{~mm}$ in diameter. The green compact is placed in between.

To characterize the reaction products, $\mathrm{X}$-ray diffraction (XRD) analysis was performed with $\mathrm{Cu} \mathrm{K}_{\alpha}$ radiation. Raman spectroscopy was performed using a dispersive Raman microscope with a confocal depth resolution of $2 \mu \mathrm{m}$, spectral resolution of $\mathrm{b} 3 \mathrm{~cm}^{-1}$ and spectral range between 160 and $3500 \mathrm{~cm}^{-1}$ by $785 \mathrm{~nm}$ laser. Spectra were taken from different points of the samples to determine the homogeneity and to identify various compounds formed in the samples. Also, microstructures of the products were studied $\mathrm{u}$ sing a field emission scanning electron microscope (FESEM, Cambridge S360).

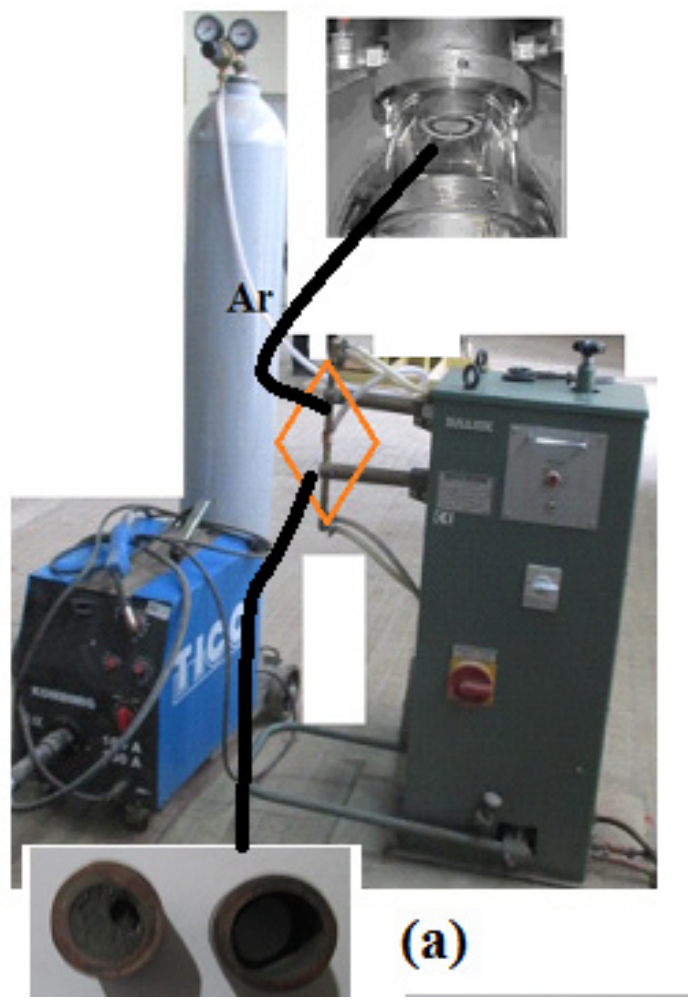

Figure 1. Schematic representation of ETER-VC chamber and produced samples (b) 
The wear resistance and the friction coefficient will be performed in the near future. The microhardness $(\mathrm{H})$, the elastic modulus (E) and the toughness $\left(\mathrm{K}_{\mathrm{IC}}\right)$ of the fabricated samples were measured under ambient conditions using the instrumented Vickers indentation method (ZwickRoell, ZHU 2.5 apparatus).

The impression diagonal (2a) was measured, and the hardness values were calculated according to the following relation:

$$
\mathrm{H}_{\mathrm{v}}=(1.8544 \mathrm{P}) /(2 \mathrm{a})^{2}
$$

The fracture toughness was also calculated by indentation fracture (IF) method according to the equation:

$$
\mathrm{K}_{\mathrm{IC}}=0.16 \mathrm{H}_{\mathrm{v}} \mathrm{a}^{1 / 2}(\mathrm{c} / \mathrm{a})^{-3 / 2}
$$

Where $\mathrm{H}_{\mathrm{v}}$ was the Vickers hardness, a was the half-length of the indentation diagonal and $\mathrm{c}$ was the half-length of the median crack generated by indentation. Generally, the fracture toughness measured by IF method were fluctuating values with relatively large deviations due to the phase distribution and measurement errors of calculation. Thus, a linear regression model was applied to get a reliable value of indentation fracture toughness [42].

To obtain the values of $\mathrm{A}, \mathrm{B}$ and $\mathrm{R}^{2}$, a series of indentation loads $(10 \mathrm{~N}, 50 \mathrm{~N}, 100 \mathrm{~N}, 300,500 \mathrm{~N})$ were applied to get the relations of $\mathrm{P}$ and $\mathrm{c}^{3 / 2}$

Where $\mathrm{P}$ is the indentation load. Through the combination of Eqs.(5) and (6), a linear relation between $P$ and $\mathrm{c}^{3 / 2}$ was obtained:

$$
\mathrm{P}=\mathrm{Ac} \mathrm{c}^{3 / 2}+\mathrm{B}\left(\mathrm{A}=\mathrm{K}_{\mathrm{IC}} / 0.075\right)
$$

\section{Results and Discussion}

\subsection{Thermodynamic Calculations}

The aluminothermic reaction of titanium oxide in the presence of iron considered in the present work is as follows:

$$
3 \mathrm{TiO}_{3}+4 \mathrm{Al}+3 \mathrm{C}+\mathrm{xFe} \rightarrow 3 \mathrm{TiC}+2 \mathrm{Al}_{2} \mathrm{O}_{3}+x \mathrm{Fe}
$$

According to thermodynamic data, in the absence of $\mathrm{Fe}$, the enthalpy of this reaction is extremely negative and hence it is considerably exothermic, but the addition of iron decreases the heat released from this reaction. So, before experimental investigations, thermodynamic calculations were performed to determine the range that iron can be added to reaction $2(\mathrm{x})$ and still it will heated.In exothermic reactions, if the conditions are assumed to be adiabatic, the heat liberated from the reaction can increase the final temperature of the wares. The highest temperature that a reaction system can reach is adiabatic temperature $\left(T_{a d}\right)$ and can be calculated using the following formula [7]:

$$
\begin{gathered}
\Delta H=\int_{298}^{T_{t r}} n C_{p} \text { (products) } d T \\
+n \Delta H_{\text {tr }}+\int_{T_{t r}}^{a d} n C_{p} \text { (products) } d T
\end{gathered}
$$

Is the difference between the formation of molar enthalpy of the products and raw materials at $298 \mathrm{~K}, \mathrm{n}$ is the mole of each product and $\mathrm{C}_{\mathrm{p}}$ is the molar heat capacity? If there is any phase change in products during heating, it should be considered in the calculations. So, in the previous formula, $T_{\text {tr }}$ is the transformation temperature and $\Delta \mathrm{H}_{\text {tr }}$ is the molar enthalpy of transformation. Also, if a material is added to the reaction as diluents, its heat capacity should be added to the product's heat capacity. Combustion wave is dependent on the heat generation by the reaction and heat dissipation to the surrounding area and remaining reactants. The low adiabatic temperature of a reaction indicates that the heat generated by this reaction is low and therefore this reaction cannot propagate in a stable mode [8]. According to the experimental criterion of Merzhanov [8, 9], in an exothermic reaction if the calculated adiabatic temperature is higher than $1800 \mathrm{~K}$, it can be volume combustion and the process is (ETER-VC). The effect of $\mathrm{Fe}$ additions on the adiabatic temperature of reaction2 is shown in Fig. 1. Also, thermodynamic data used for calculating the adiabatic temperature is presented in Table 1. According to Fig. 2, adiabatic temperature of the aluminothermic reaction of titanium oxide is $2371 \mathrm{~K}$ and addition of iron decreases it with a non-uniform trend. The two steps at $2325 \mathrm{~K}$ and $1809 \mathrm{~K}$ are above calculations, the amounts of $\mathrm{Fe}$ added to the reaction were between 0 and 60 wt.\%. $60 \%$ of theoretical density was prepared associated with the melting of alumina and iron, respectively. According to thermodynamic calculations, if the iron added to the reaction is lower than 53.14 wt. \%, adiabatic temperature is higher than $1800 \mathrm{~K}$ and it is expected that the reaction will be volume combusted.

Table 1. Data of adiabatic temperature (K) function of the iron concentration (wt. \%)

\begin{tabular}{|c|c|c|c|}
\hline $\mathbf{x}$ & $\mathbf{T}_{\mathbf{a d}}$ & & Fe weight \\
\hline 0.00 & 2328 & $(1)$ & $0.0 \%$ \\
\hline 2.30 & 2328 & $(2)$ & $27.7 \%$ \\
\hline 2.50 & 2294 & & $29.4 \%$ \\
\hline 3.00 & 2217 & & $33.3 \%$ \\
\hline 3.50 & 2144 & & $36.8 \%$ \\
\hline 4.00 & 2077 & & $40.0 \%$ \\
\hline 4.50 & 2013 & & $42.8 \%$ \\
\hline 5.00 & 1954 & & $45.4 \%$ \\
\hline 5.50 & 1898 & & $47.8 \%$ \\
\hline 6.00 & 1845 & & $50.0 \%$ \\
\hline 6.35 & 1810 & $(3)$ & $51.4 \%$ \\
\hline 7.85 & 1810 & $(4)$ & $56.6 \%$ \\
\hline 8.00 & 1797 & & $57.1 \%$ \\
\hline 8.50 & 1762 & & $58.6 \%$ \\
\hline 9.00 & 1727 & & $60.0 \%$ \\
\hline
\end{tabular}

(1) Melting temperature of alumina; percentage of melted alumina $=99 \%$

(2) Melting temperature of alumina; percentage of melted alumina $=0 \%$

(3) Iron melting temperature; percentage of molten iron $=100 \%$

(4) Iron melting temperature; percentage of molten iron $=0 \%$ 


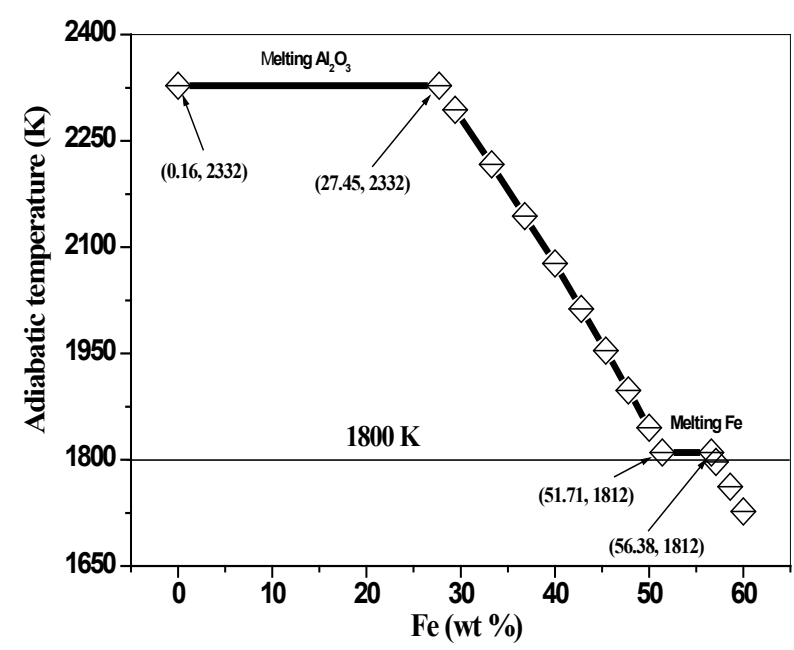

Figure 2. Effect of Fe additions on adiabatic temperature of reaction 2

The adiabatic temperature for reaction 2 with 10 and 20 wt. \% Fe is $2325 \mathrm{~K}$ which is considerably higher than the Merzhanov criterion $(1800 \mathrm{~K})$. This criterion is based on experimental results and it is verified in many ETER-VC in comparison with SHS reaction systems [8]. So, to reveal the reason(s) why it is not applicable for reaction2, phase analysis was performed on the products to investigate the effect of iron addition on phases formed after volume combustion.

The calculation of theoretical adiabatic temperature for this reaction suggests that iron can be added to this reaction up to 56.38 wt. $\%$ and it will remain volume combustion according to Merzhanov criterion [8]. But first experimental investigations showed that in the sample containing $30 \mathrm{wt} . \% \mathrm{Fe}$, the reaction only happened in a thin top surface layer of the compacted powder and then it ended which means that the reaction does not propagate in the ETE-VC mode for this sample. These results are inconsistent with the theoretical results. XRD analysis indicated that the reaction products consist of $\mathrm{TiC}, \mathrm{Al}_{2} \mathrm{O}_{3}$ and $\mathrm{Fe}_{3} \mathrm{Al}$ intermetallic phases. These reaction products are not the same as the product of reaction2, because in this reaction it was expected that $\mathrm{Fe}$ would not participate in the reaction and act only as a diluent's agent. But experimental results showed that some of the aluminum was reacted with iron to form a Fe ${ }_{3} \mathrm{Al}$ phase. This temperature range is lower than that for ignition of the reaction between aluminum and $\mathrm{TiO}_{2}(1173 \mathrm{~K})$ [13]. So, with the reaction of some of $\mathrm{Al}$ with $\mathrm{Fe}$, there will be lack of aluminum for complete reduction of all the $\mathrm{TiO}_{2}$ to Ti. Choi and Rhee [13] indicated that reduction of $\mathrm{TiO}_{2}$ with aluminum proceeds by way of $\mathrm{Ti}_{3} \mathrm{O}_{5}, \mathrm{Ti}_{2} \mathrm{O}_{3}$

\subsection{XRD Investigations}

XRD analysis of the samples which contains 20 to 40 wt. $\% \mathrm{Fe}$ is demonstrated in Fig. 3. The only phases formed in the sample without $\mathrm{Fe}$ addition are titanium carbide (TiC, ICDD card no. 00-003-1213) with a cubic crystal structure and aluminum oxide $\left(\alpha-\mathrm{Al}_{2} \mathrm{O}_{3}\right.$, ICDD card no. 01-071-1126) with rhombohedral (hexagonal) crystal structure. The addition of $10 \mathrm{wt} . \% \mathrm{Fe}$ had no considerable effect on XRD spectra, but in samples containing 20 and 40 wt.\% Fe, we observe the appearance of iron aluminide in the products $\left(\mathrm{Fe}_{3} \mathrm{Al}\right.$, ICDD card no. 00-045-1203) with a cubic crystal structure. So, reaction products formed in the reactions containing $\mathrm{Fe}$ were not as the same as predicted by reaction 2 . The lattice parameter of titanium carbide was calculated from the XRD patterns using Brag's equation and Nelson-Riley function $[3,25]$.
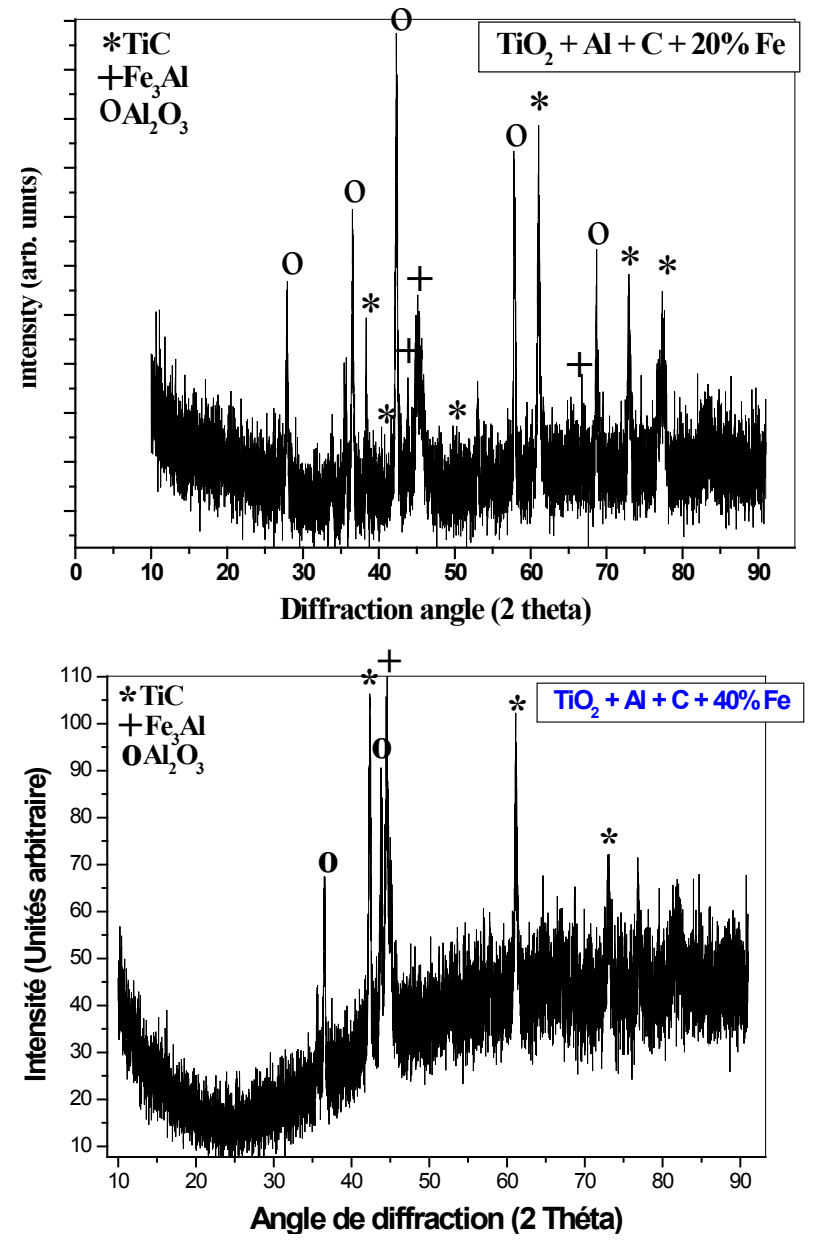

Figure 3. XRD analysis of samples with 20 and $40 \mathrm{wt} . \% \mathrm{Fe}$

$$
\begin{gathered}
a=a_{0}+a_{0} K_{r} \frac{1}{2}\left(\frac{\cos ^{2} \theta}{\sin \theta}+\frac{\cos ^{2} \theta}{\theta}\right)=a_{0}+K^{\prime \prime}(\theta) \\
\text { Nelson-Riley function } \\
\mathrm{a}=\mathrm{d}_{(\mathrm{hkl})}\left(\mathrm{h}^{2}+\mathrm{k}^{2}+\mathrm{l}^{2}\right)^{1 / 2} \text { Brag equation }
\end{gathered}
$$

Where $\theta$ is diffraction angle, is the lattice parameter which is determined by Eq.(12) and $\mathrm{a}_{0}$ is the true lattice parameter of $\mathrm{TiC}$ which is calculated by Eq.(8). Using XRD patterns, we can draw the variations of lattice parameter versus Nelson-Riley function and extrapolate the true lattice parameter at $\theta=90$. Fig. $4 \mathrm{a}$ and $\mathrm{b}$ shows Nelson-Riley function diagrams used for calculating lattice parameter of $\mathrm{TiC}$ in samples containing 20 and 40 
wt. \% Fe and variations of synthesized TiC lattice parameters with iron addition, respectively. Also, the lattice parameter of stoichiometric $\mathrm{Ti}_{0.5} \mathrm{C}_{0.5}$ is indicated in the Fig. 4.

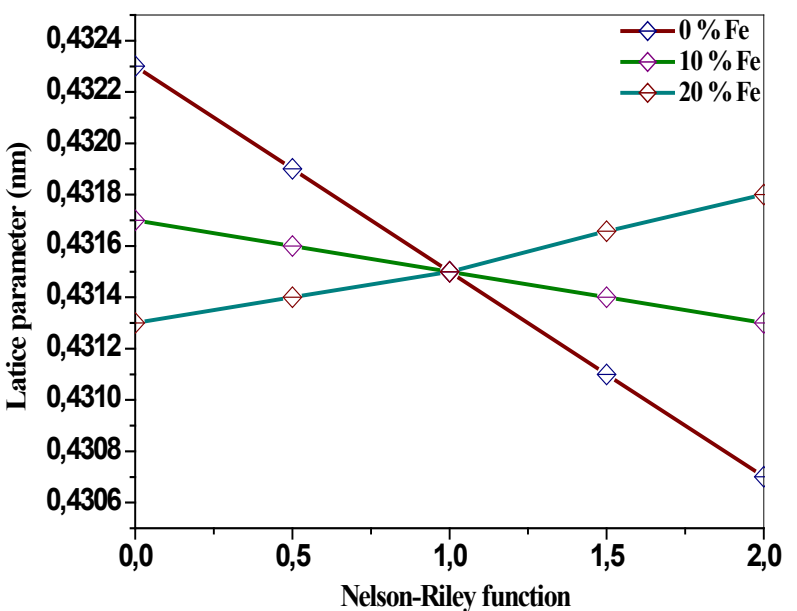

(a)

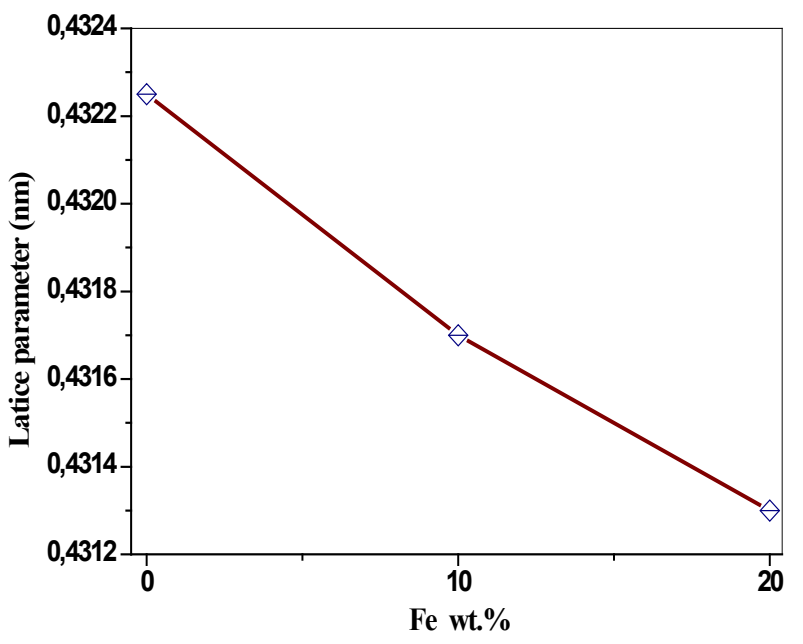

(b)

Figure 4. a: Nelson-Riley function diagram for samples with different $\mathrm{Fe}$ contents and $\mathbf{b}$ : variations of $\mathrm{TiC}$ lattice parameter with $\mathrm{Fe}$ additions

As can be understood, the lattice parameter of titanium carbide in the sample synthesized without $\mathrm{Fe}$ is lower than that of the stoichiometric one and decreases with the increase of $\mathrm{Fe}$ content in the reaction this result is in agreement with Raman spectroscopy measurement.

Different literature that used Self propagating high temperature synthesis (SHS) for $\mathrm{TiC}$ and composites containing this compound showed that during combustion synthesis, carbon content in the $\mathrm{TiC}$ is usually lower than stoichiometric and therefore its formulation represented as $\mathrm{TiC}_{1-\mathrm{x}}(\mathrm{x} \leq 1)[3,26,27]$. Storms [27] indicated that by decreasing carbon content, lattice parameter of $\mathrm{TiC}$ falls. So, a possible reason for lower lattice parameter of $\mathrm{TiC}$ in the sample with higher Fe may be decreasing carbon of this phase. Another reason for this phenomenon may be the dissolution of oxygen in the crystal structure of $\mathrm{TiC}$ and formation of titanium oxy-carbide. Titanium carbide (TiC) has a $\mathrm{NaCl}$ face centered cubic (FCC) crystal structure. $\mathrm{TiO}$ also has the same crystal structure of TiC. So, they can form a series of continuous solid solutions like $\mathrm{TiC}_{1-\mathrm{x}} \mathrm{O}_{\mathrm{x}}$ $(0 \leq x \leq 1)$. Titanium oxy-carbide $\left(\mathrm{TiC}_{1-\mathrm{x}} \mathrm{O}_{\mathrm{x}}\right)$ is an intermediate produce usually observed during carbothermal reduction of $\mathrm{TiO}_{2}$. Jiang et al. showed that as $\mathrm{TiO}$ increases in the titanium oxy-carbide phase, lattice parameter of this phase falls from $0.4324 \mathrm{~nm}$ for TiC to 0.4194 for $\mathrm{TiO}$ [28]. and $\mathrm{TiO}$ mid-products to form $\mathrm{Ti}$ and $\mathrm{Al}_{2} \mathrm{O}_{3}$. Similar results were presented by Khoshhal and co-workers [19] and Zou et al. [40] during aluminothermic reduction of ilmenite. Because there was not any peak related to the $\mathrm{TiO}_{2}$ in the XRD patterns and the characteristic peaks of this phase in the Raman spectra were weak, so it is expected that the quantity of this phase is low in all samples. Therefore, the lack of aluminum for complete reduction of $\mathrm{TiO}_{2}$ caused partial reduction of it and formation of lower titanium oxide like $\mathrm{Ti}_{3} \mathrm{O}_{5}, \mathrm{Ti}_{2} \mathrm{O}_{3}$ and $\mathrm{TiO}$ and $\mathrm{Al}_{2} \mathrm{O}_{3}$. Then these oxides reacted with carbon to form oxy-carbide $\left(\mathrm{TiC}_{1-\mathrm{x}} \mathrm{O}_{\mathrm{x}}\right)$ as indicated by XRD analysis through decreasing of lattice parameter of $\mathrm{TiC}$ and characteristic peaks of this phase in Raman spectroscopy results. Comparing the lattice parameter calculated for $\mathrm{Ti}(\mathrm{C}, \mathrm{O})$ in the sample containing $20 \mathrm{wt} . \% \mathrm{Fe}$ with that proposed by Jiang et al.[28], it is anticipated that the maximum oxygen content of titanium oxy-carbide (x) will be 0.3 and so the chemical formula of the oxy-carbide is $\mathrm{TiC}_{0.7} \mathrm{O}_{0.3}$ in this sample. The presence of $\mathrm{TiO}_{2}$ peaks in the Raman spectra of samples containing 10 and $20 \mathrm{wt} . \% \mathrm{Fe}$ may be because of this fact that raw materials were not uniform and adding $\mathrm{Fe}$ to them raised the distance between $\mathrm{TiO}_{2}$ and $\mathrm{Al}$ particles. So, in some places of the compacts, $\mathrm{Al}$ and $\mathrm{TiO}_{2}$ might not be in contact together and therefore no reduction happened. In reaction 2 , it was expected that all the carbon reacts with $\mathrm{Ti}$ to form stoichiometric titanium carbide. But, Raman analysis of the sample with no Fe showed characteristic peaks of un-reacted carbon. In other words, it indicated that in the aluminothermic reduction of $\mathrm{TiO}_{2}$, all the carbon did not react with the titanium. So, the titanium carbide formed would not be a stoichiometric one and its chemical formula is $\operatorname{TiC}_{\mathrm{x}}(\mathrm{x} \leq 1)$. This result is in agreement with the difference observed in Fig. 6 between the lattice parameters of the stoichiometric $\mathrm{TiC}$ and that measured for synthesized $\mathrm{TiC}$ in the sample with no $\mathrm{Fe}$. When the amount of $\mathrm{Fe}$ added to the reaction increased, more aluminum was used in the reaction with $\mathrm{Fe}$, so the volume fraction of reduced Ti falls. As a result, the quantity of titanium oxide mid products and the possibility for the formation of titanium oxy-carbide with higher oxygen content and lower lattice parameter increased as shown in Fig. 6. Also, the increase of oxygen in the titanium oxide mid-product and the decrease of combustion temperature with the addition of Fe reduced the amount of carbon participated in the reaction and led to the increase in volume fraction of un-reacted carbon in the 
final products as indicated by the amplification of carbon peaks in the Raman spectra of samples with higher Fe contents (Fig. 7d). It should be noted that the possibility of reducing the remaining $\mathrm{TiO}_{2}$ with excess carbon (carbothermal reaction) in the samples containing $\mathrm{Fe}$ is low due to the two following reasons: first, according to thermodynamic data, the standard Gibbs free energy of the reaction between $\mathrm{TiO}_{2}$ and carbon is positive below $1473 \mathrm{~K}$ and therefore this reaction proceeds at very high temperatures (1973-2373 K) in argon atmosphere [25]. As indicated in Fig. 1, the adiabatic temperature of the aluminothermic reaction is $2371 \mathrm{~K}$ and adding $\mathrm{Fe}$ to the reaction decreased it considerably. Usually, the combustion temperature of an ETE-VC reaction is lower than the adiabatic temperature due to the heat loss to the surrounding area $[7,8,15]$. So, it is expected that as the Fe was added to the reaction, the combustion temperature decreased which lowered the possibility of carbothermic reaction. Second, carbothermal reduction of $\mathrm{TiO}_{2}$ needs high reaction times (10-24 h) [25]. But, the reaction times for small SHS samples are in the range of seconds to a few minutes. So, one can expect that although this reaction can happen during SHS of the present samples, especially in the samples with lower $\mathrm{Fe}$ contents due to their higher combustion temperature, but the extent of its propagation was not high and therefore the amount of carbon used for carbothermic reduction of $\mathrm{TiO}_{2}$ was negligible. According to the above Results and Discussion sections, it is expected that the right pass for reaction 2 will be as follows: Fig. 9 shows the effect of $\mathrm{Fe}$ on adiabatic temperature of reaction 6 which was estimated using the thermodynamic data of Table 1 with this assumption that at low oxygen content, the thermodynamic properties of titanium oxy-carbide $\left(\mathrm{TiC}_{1-\mathrm{x}} \mathrm{O}_{\mathrm{x}}\right)$ are the same as those of titanium carbide (TiC). The effect of $\mathrm{Fe}$ on adiabatic temperature of reaction2 is also shown on the figure for comparison. It is observed that the adiabatic temperatures of reaction 6 were 1916 and $1421 \mathrm{~K}$ for the samples containing 15 and $20 \mathrm{wt}$ \% $\mathrm{Fe}$ which are respectively higher and lower than Merzhanov criterion. So, these new calculated values are consistent with the Merzhanov criterion and experimental observations shown in Fig. 4. As shown earlier in Fig. 4, the reaction is stable for the sample containing $15 \mathrm{wt} \% \mathrm{Fe}$, but, not stable for the sample containing $20 \mathrm{wt}$ \% Fe. So, the Merzhanov criterion is satisfied between these two values as indicated in Fig. 9. It is worse noting that if 20 wt. $\% \mathrm{Fe}$ is added to reaction6, the amount of oxygen $(\mathrm{x})$ in theta $\left(\mathrm{C}_{1-\mathrm{x}} \mathrm{O}_{\mathrm{x}}\right)$ phase will be 0.29 . This result is in agreement with the lattice parameter of titanium oxy-carbide purposed by Jiang [28] and that was calculated in Fig. 6.

The quantification analysis will be used to calculate the phase of TiC from XRD using Rietveld affinement [25].

\subsection{Microstructural Analysis}

The FESEM microstructures of the surfaces of samples are illustrated in Fig. 5. Indicate the presence of higher density in the final structure of the products [8]. The microstructure of the sample with no Fe consists of large $\mathrm{Al}_{2} \mathrm{O}_{3}$ grains and TiC particle sintered together (Fig. 5a). The addition of $10 \mathrm{wt} . \% \mathrm{Fe}$ to the reaction changed the morphology of $\mathrm{Al}_{2} \mathrm{O}_{3}$ from the large plate like grains to slightly finer grains with near spherical morphology. Also, $\mathrm{TiC}$ grain size decreased and they became almost spherical in this sample (Fig. 5b).

In the sample containing $20 \mathrm{wt} . \% \mathrm{Fe}$, the $\mathrm{TiC}$ particles became finer, with a particle size between 2 and $6 \mu \mathrm{m}$ (Fig. $5 \mathrm{c}$ and d). It is interesting to notice that there is repeating step on some surfaces of the $\mathrm{TiC}$ particles. These steps are characteristics of crystal growth with interface-controlled growth mechanism. Usually, crystal growth in the vapor phase or melt is controlled by three different mechanisms, including diffusion in the melt or vapor, latent heat flow from the crystal-melt interface and reaction at the crystal interface or interface-controlled continuous and lateral growths. growth [36]. The interface-controlled growth mechanism is divided into two different categories named. 

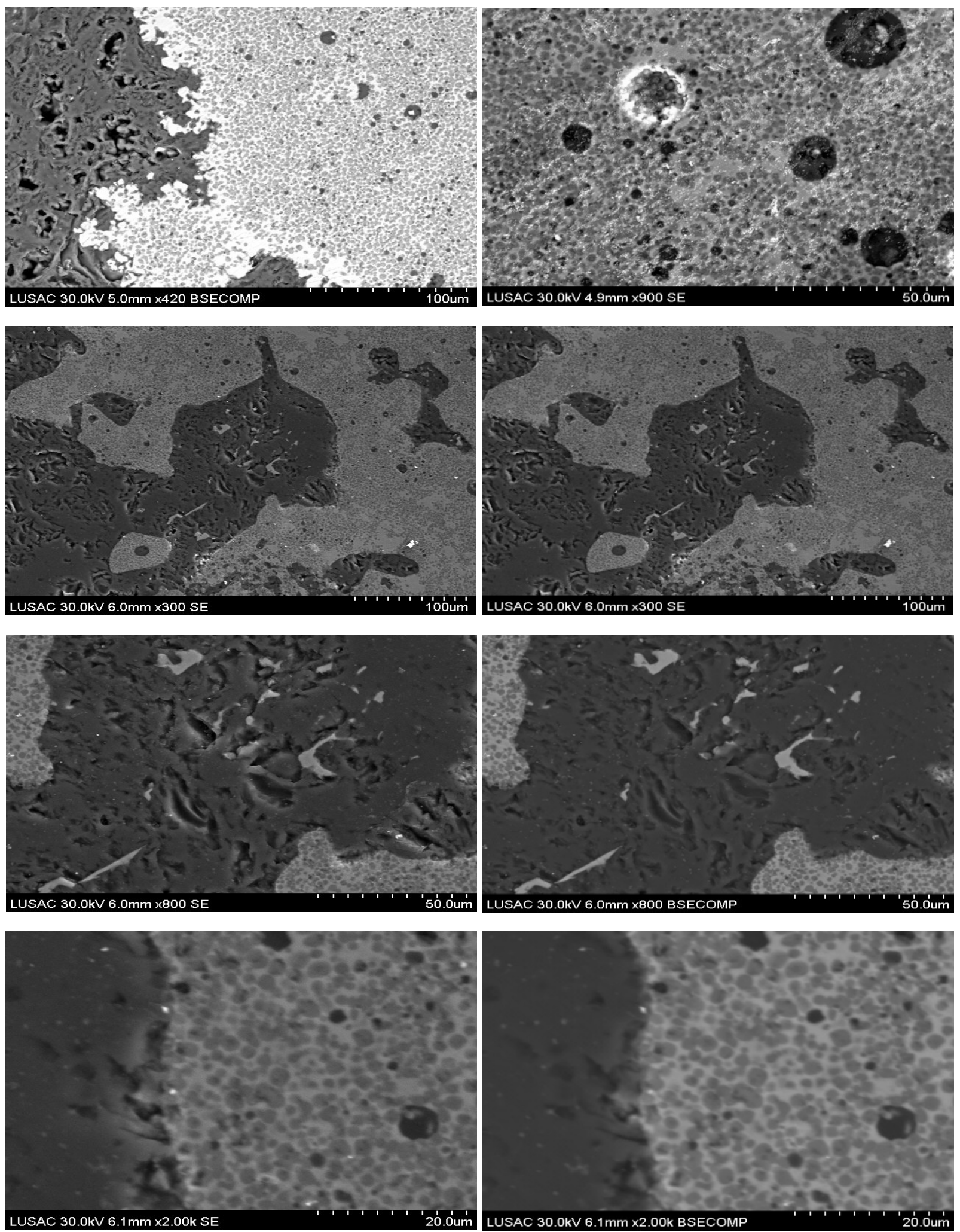

Figure 5a. ESEM microstructures of polished and etched surface of samples with $10 \mathrm{wt} . \% \mathrm{Fe}$ 

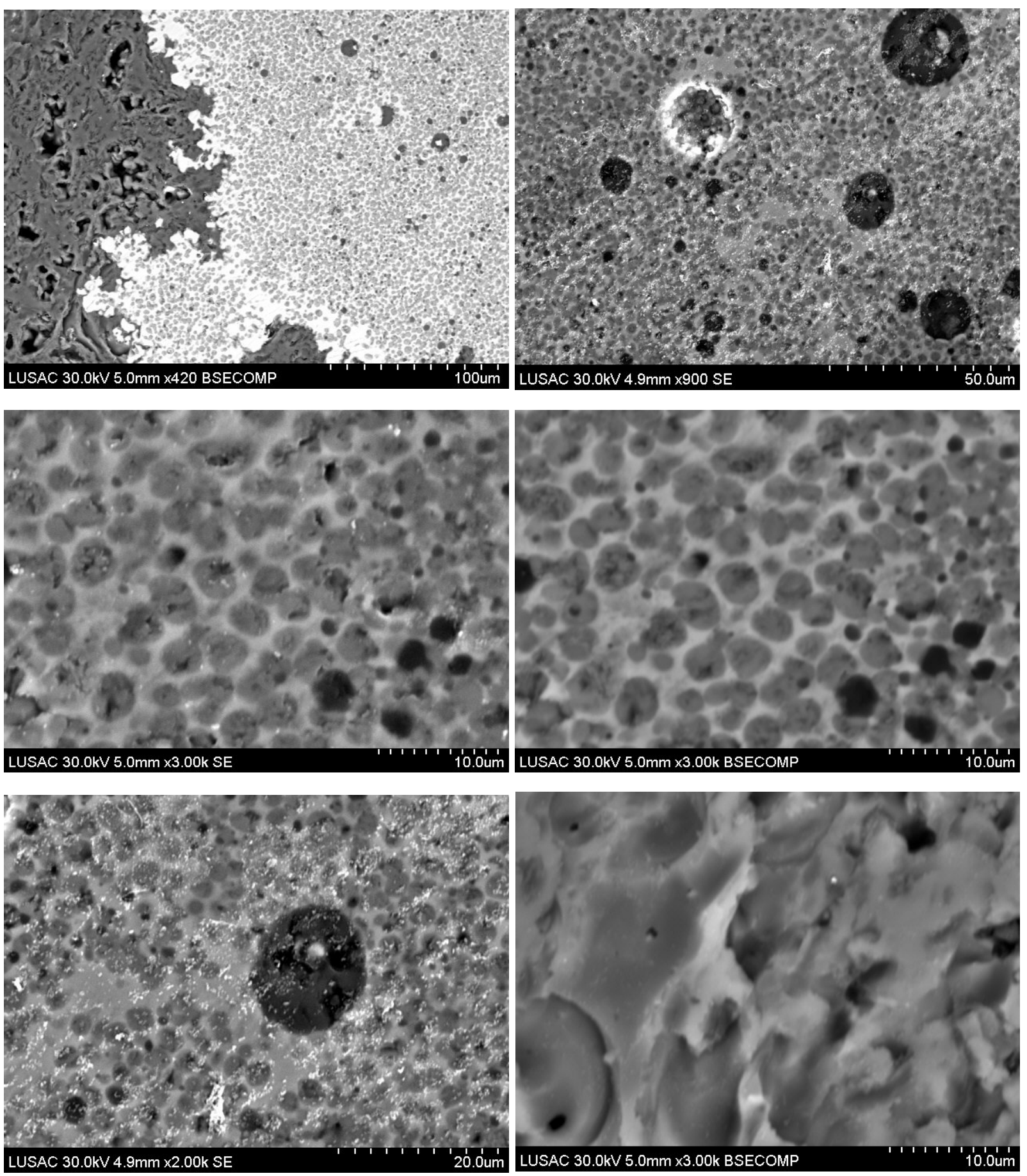

Figure 5b. FESEM microstructures of polished and etched surface of samples with $20 \mathrm{wt} . \% \mathrm{Fe}$ 

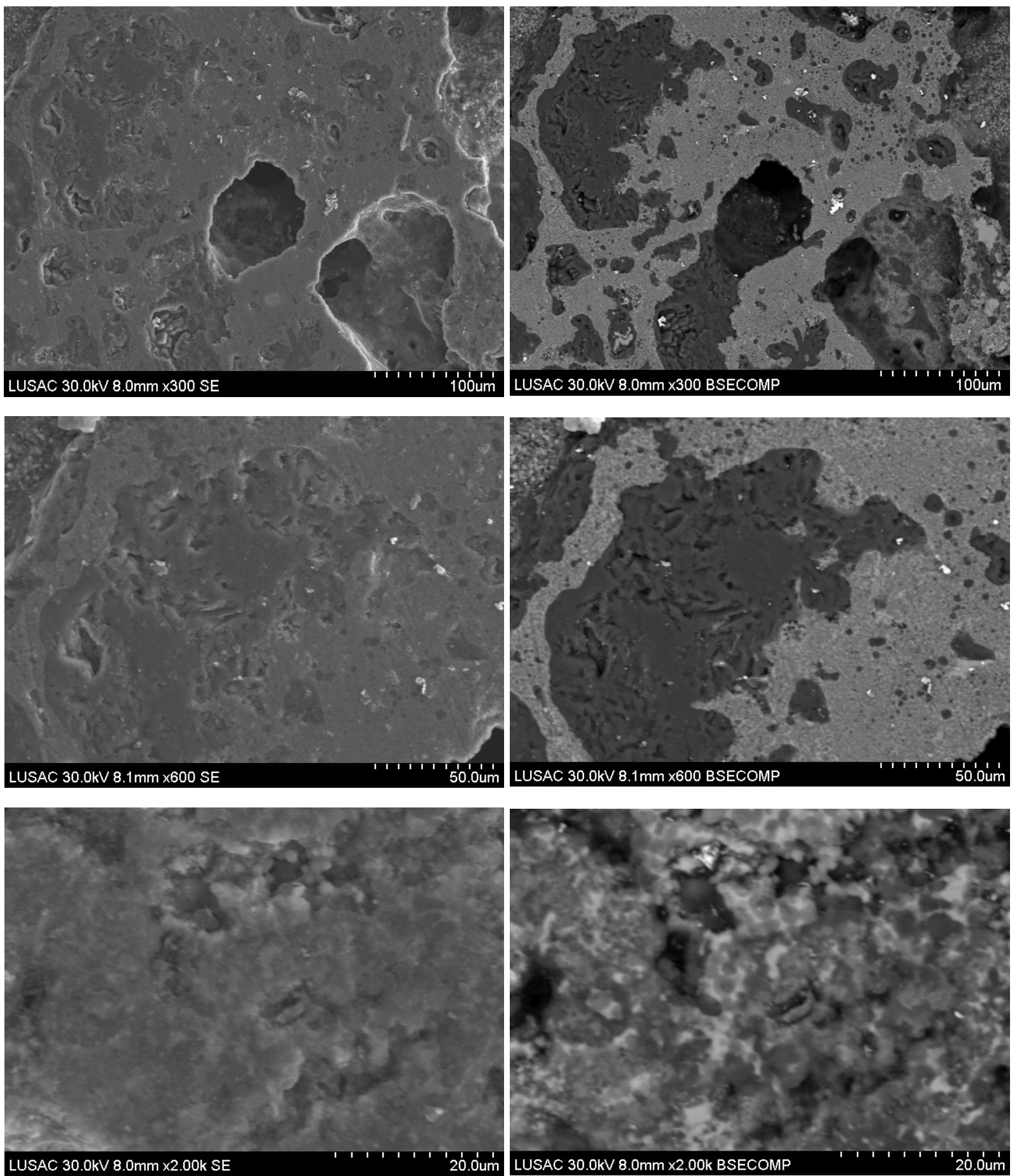

Figure 5c. FESEM microstructures of polished and etched surface of samples with $40 \mathrm{wt} . \% \mathrm{Fe}$

In continuous growth, atoms can attach to the crystal surface at any point of the growing surface. In these conditions the interface grows uniformly. But lateral growth leads to the movement of a step across the interface and the atoms only can attach to the step. The step height can be one, several or a great number of atom layers (macro steps) depending on its lateral growth rate and will be higher for a layer with a slower edge growth rate. There are two types of lateral mechanisms, as surface nucleation and screw dislocation. In surface nucleation mechanism, new steps are nucleated on top of each other and form a pyramid-like interface [37]. On the other hand, the screw dislocation model proposed by Hilling and Turnbull [38] puts on that screw dislocations emerge from the growing crystal face and cause the formation of repeating step like an Archimede an spiral [36]. There are some evidences for the formation of two-dimensional nuclei on some surfaces of $\mathrm{TiC}$ particles. So, it seems that surface nucleation-interface controlled growth mechanism is the growth controlling mechanism of $\mathrm{TiC}$ particles in this 
sample. Fig. 8a and $b$ shows the different magnifications of the fracture surface in the sample containing $20 \mathrm{wt}$. \% Fe. It can be seen that TiC particle size decreased slightly, but their morphology is transformed into cubical particles with faceted morphology. According to the statements of Kirk Patrick faceted [36], taught there is not a theoretical justification, Cahn et al. suggested that crystals with non-faceted morphology grow by continuous mechanism while crystals with faceted morphology, grow with lateral growth mechanism. Choi and Rhee [13] suggested that the aluminothermic reduction of $\mathrm{TiO}_{2}$ is controlled by the diffusion of carbon through solid TiC. So, it seems that the addition of $\mathrm{Fe}$ to the reaction changed the mechanism

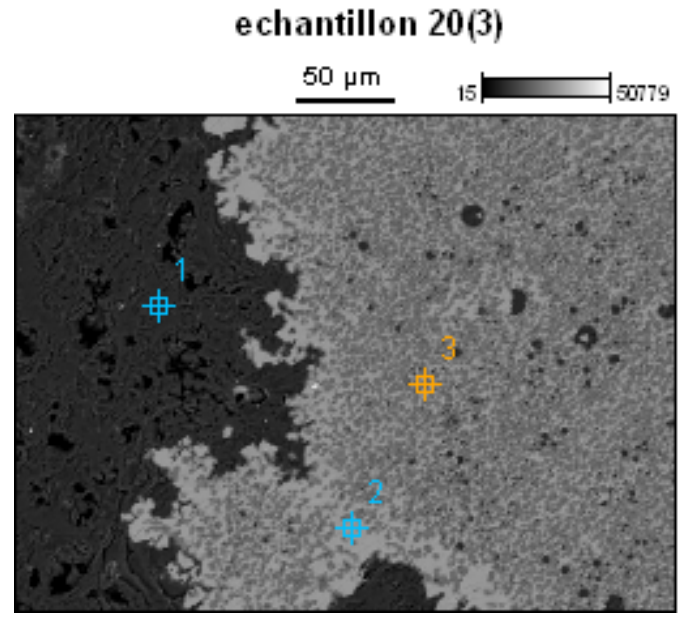

echantillon 20(3)_pt2

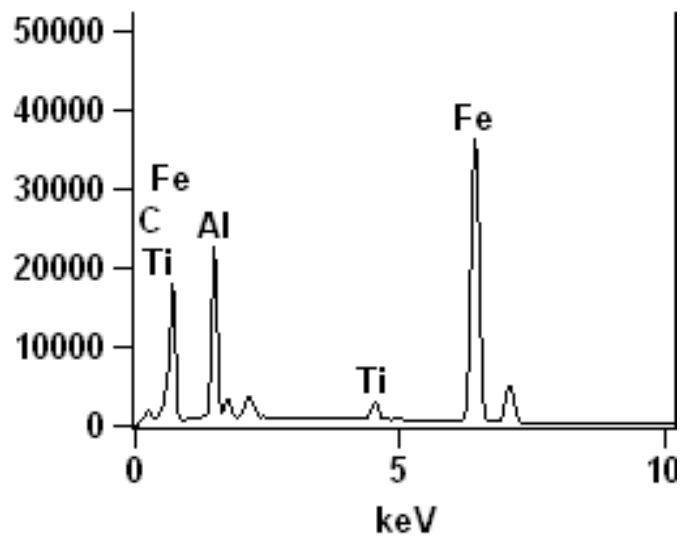

controlling the growth of $\mathrm{TiC}$ particles from diffusion-controlled growth in the sample without $\mathrm{Fe}$ to lateral growth interface controlled mechanism for samples containing Fe higher that $10 \mathrm{wt} . \%$. The addition of higher $\mathrm{Fe}$ to the reaction caused the decrease of $\mathrm{TiC}$ particle size and porosity volume fraction in this ample.

In the Fig.6, the microstructural representation and EDS analysis displays elemental analyses of the various regions of the samples. Secondary electron image, atomic concentration cartographies of $\mathrm{Ti}, \mathrm{C}, \mathrm{Al}$ and $\mathrm{C}$ are also illustrated. EDS spectra and was used to determine the elemental composition of the different regions in the sample with Fe addition and are presented at the Fig. 7.

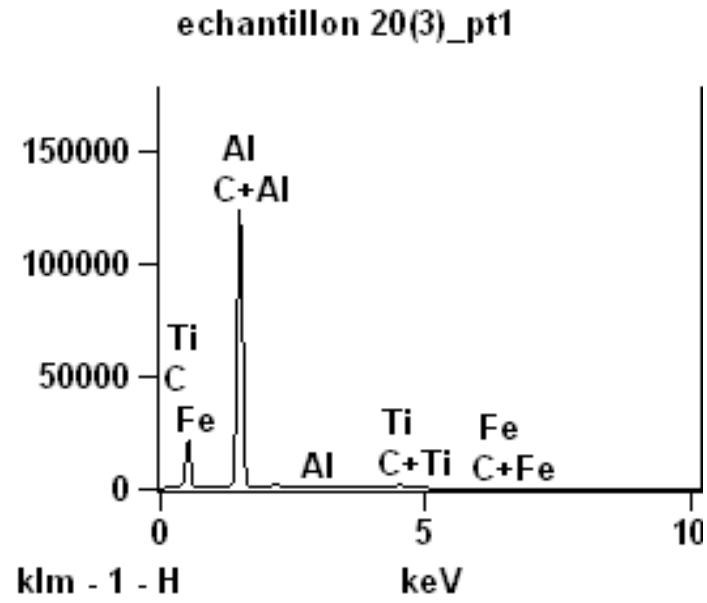

$$
\text { echantillon 20(3)_pt3 }
$$

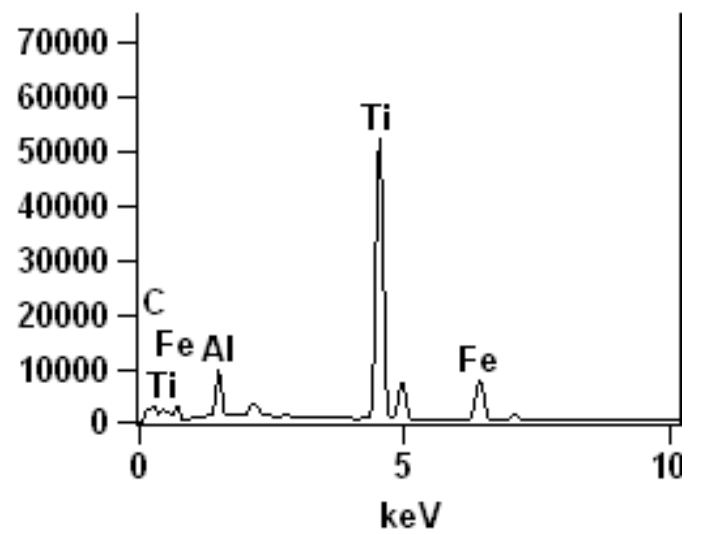

Atom Weight $\%$

\begin{tabular}{|c|c|c|c|c|}
\hline & $\mathrm{C}-\mathrm{K}$ & $\mathrm{Al}-\mathrm{K}$ & $\mathrm{Ti}-\mathrm{K}$ & $\mathrm{Fe}-\mathrm{K}$ \\
\hline 20 wt.\% $\mathrm{Fe}-\mathrm{Pt}_{1}$ & 13.34 & 80.31 & 5.71 & 0.64 \\
\hline 20 wt.\% $\mathrm{Fe}-\mathrm{Pt}_{2}$ & 1.50 & 15.28 & 2.29 & 80.93 \\
\hline 20 wt.\% $\mathrm{Fe}-\mathrm{Pt}_{3}$ & 2.53 & 5.88 & 69.59 & 22.00 \\
\hline
\end{tabular}

Figure 6. EDX spectra in different region of the high performance composite of polished and etched surface 

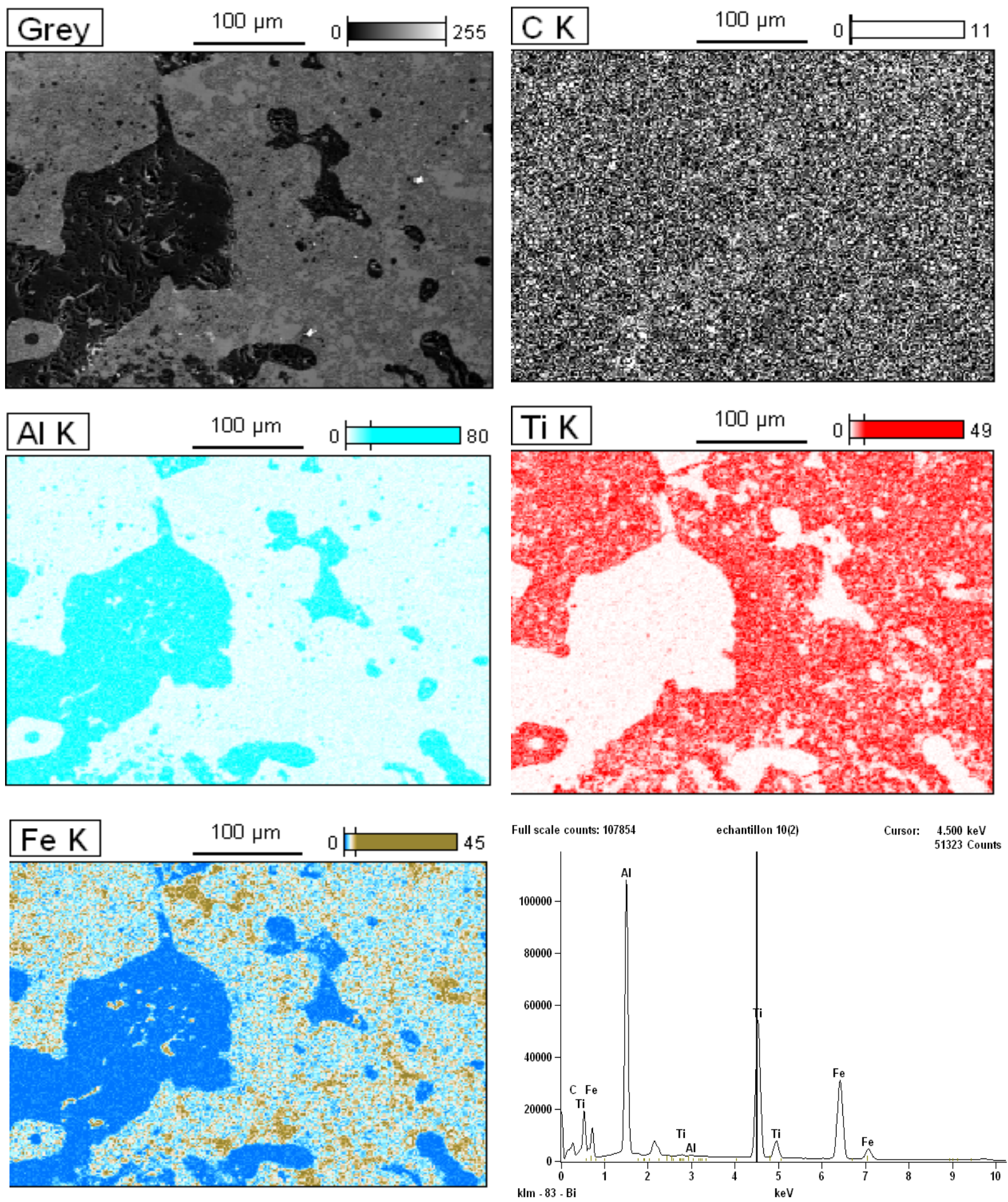

Figure 7. Microstructural representation of produced samples, analysis displays elemental analyses of the various regions of the sintered samples. Secondary electron image, atomic concentration cartographies of $\mathbf{F e}, \mathbf{T i}, \mathbf{A l}$ and $\mathbf{C}$ of polished and etched surface.

\subsection{Raman Spectroscopy}

Raman microscopy is able to determine phases for polymorphic solids at the microscopic level. This is its advantage over conventional X-ray diffraction spectrometry in which the sample volume cannot be too small. Phase identification with Raman spectroscopy uses the characteristic vibration band(s) associated with a certain phase in a solid. This analysis is founded on the Raman scattering of electromagnetic radiation by atoms and molecules. When irradiating materials with electromagnetic radiation of a single frequency, the light will be scattered by molecules elastically and inelastically. The inelastic scattering is called Raman scattering and can be used to determine details of the structure of the molecule or crystal lattice [29]. 
To study the reaction products more precisely, micro-Raman spectroscopy analysis was performed on different samples. Some Raman spectroscopy analysis on titanium carbide $[30,31]$ reported that the stoichiometric titanium carbide has no Raman active mode and the Raman scattering in this carbide is caused by the disorder induced by carbon vacancy. Fig. 8a shows the results of the Raman spectroscopy analysis in the samples containing 0,10 and 20 wt. \% Fe, respectively. In the sample without $\mathrm{Fe}$, five different peaks can be observed (Fig. 8a). The first three peaks between 244 and 255, 414 and 422 and 598 and 601 $\mathrm{cm}^{-1}$ are related to the titanium carbide, which is almost the same as those reported by Lohse et al. [31] and the two peaks between 1300 and 1600 are related to the un-reacted free active carbon (Fig. 8b)..

There is no separate characteristic peak related to $\mathrm{Al}_{2} \mathrm{O}_{3}$. Cava et al. [32] reported that $\mathrm{Al}_{2} \mathrm{O}_{3}$ with a cubic crystal structure has no Raman active mode while $\alpha-\mathrm{Al}_{2} \mathrm{O}_{3}$ with a hexagonal crystal structure has two Raman active modes with characteristic peaks at 380 and 420 $\mathrm{cm}^{-1}$. As shown by XRD analysis, the synthesized alumina in all samples has a hexagonal crystal structure and thus should have two characteristic peaks. But it seems that these peaks have overlapped with intense TiC characteristic peak at $420 \mathrm{~cm}^{-1}$ and could not be observed in these spectra. The addition of $10 \mathrm{wt} . \% \mathrm{Fe}$ to the reaction led to the formation of a new peak at 266, some peaks between 340 and $384 \mathrm{~cm}-1$ and two new peaks at 517 and $634 \mathrm{~cm}^{-1}$. Also, there is a broad peak between 278 and 351 $\mathrm{cm}-1$, a new peak at $649 \mathrm{~cm}-1$ and a broad peak between 680 and $950 \mathrm{~cm}^{-1}$ in the sample containing $20 \mathrm{wt} . \%$ Fe. By comparing the results of this table with the Raman spectra in Fig. 8a, it can be concluded that besides $\mathrm{TiC}$ and un-reacted carbon, there is a little $\mathrm{TiO}_{2}$ with two weak characteristic peaks at 517 and $634-649 \mathrm{~cm}^{-1}$. Also, some peaks between 266 and $384 \mathrm{~cm}^{-1}$ and two broad peaks between 550 and $620 \mathrm{~cm}^{-1}$ and 680 and $950 \mathrm{~cm}^{-1}$ are symptoms related to the formation of titanium oxy-carbide $(\mathrm{Ti}(\mathrm{C}, \mathrm{O}))$ in the final products. Getting hold of the results of XRD and Raman together, it can be concluded that the addition of $\mathrm{Fe}$ to reaction 2 led to the increase of oxygen content in the crystal structure of $\mathrm{TiC}$ and formation of titanium oxy-carbide with lower lattice parameter.

In Raman spectroscopy, the intensity of phase characteristic peaks is dependent on its quantity. Fig. 8a compares the mean spectrum of the free carbon in the samples synthesized with different $\mathrm{Fe}$ contents. It can be seen that the addition of $\mathrm{Fe}$ to the reaction increased the mean intensity and surface area of un-reacted carbon characteristic peaks. So, one can anticipate that the volume fraction of unreacted carbon is higher in the sample with more Fe content. (a)

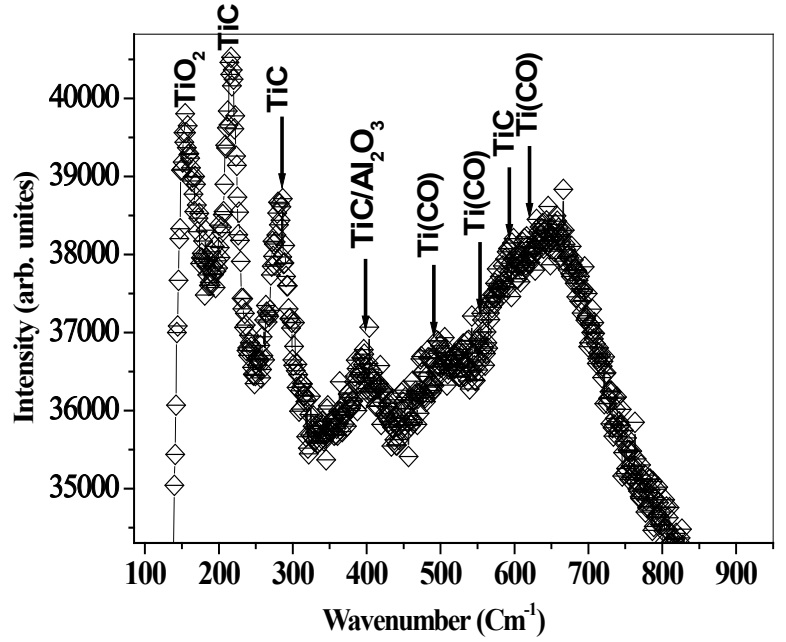

(a)

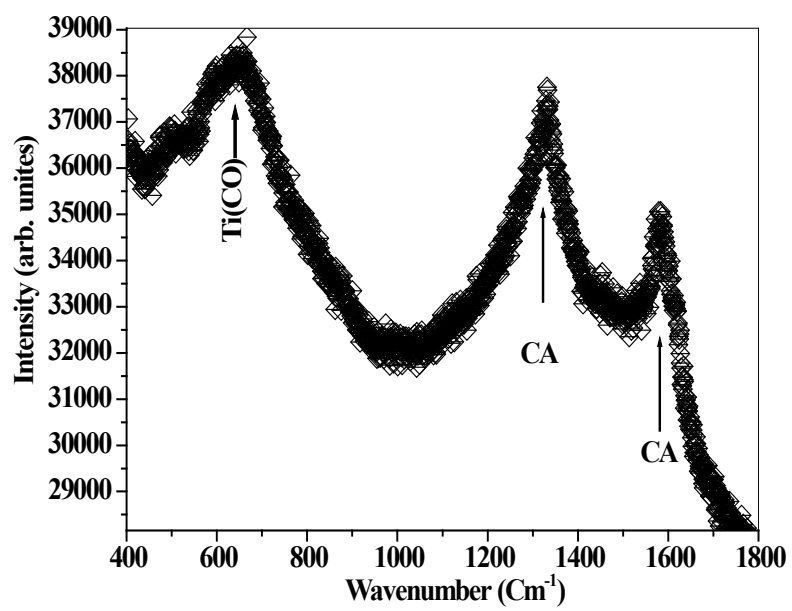

(b)

Figure 8. Raman spectroscopy analysis of samples with $20 \mathrm{wt} . \% \mathrm{Fe}$ and $\mathrm{d}$ : Raman spectra of $\mathrm{TiC}$ and Carbon active in samples with different $\mathrm{Fe}$ contents.

\subsection{Vickers Microhardness and Fracture Toughness $\left(\mathrm{K}_{\mathrm{IC}}\right)$}

According to the above results, it can be concluded that the Vickers hardness has been improved by adding \% Fe and the fracture toughness value giving a better ductility for the reinforced high performance ceramic matrix composite samples. Fig. 9 shows the hardness as a function of the applied indentation load for the same sample. The Vickers hardness increases with the increasing of the $\mathrm{wt} \%$ of Fe addition. At lower loads, the microhardness reaches a low hardness a constant value of $47.55 \mathrm{GPa}$ at $40 \mathrm{wt} \%$ of $\mathrm{Fe}$ at $\mathrm{HV}_{50}$ of the high performance ceramics matrix composites. 
Fig. 9 present the variation of Vickers microhardness of the product of reaction 2 with and without Fe addition op to 40 wt. Fe high performance ceramic matrix composite with the indentation lead. The microhardness of the composites increased almost linearly with $\mathrm{Fe}$ addition. The hardness of Carbon (28-30 GPa) is nearly 2 times the previously reported values of hardness of TiC (18 GPa). For the nearly single phase $\mathrm{Al}_{2} \mathrm{O}_{3}$ in this investigation, the microhardness was found to be $8 \mathrm{GPa}$ (measured with indentation load of $300 \mathrm{~N}$ ), which is higher than the previously reported hardness values for hexagonal in the literature. The microhardness of $\mathrm{Fe}_{3} \mathrm{Al}$ is $9.8 \mathrm{GPa}$ While the higher microhardness of the TiC- $\mathrm{Al}_{2} \mathrm{O}_{3}-\mathrm{Fe}_{3} \mathrm{Al}$ composite ceramic matrix is at higher wt. $\% \mathrm{Fe}$ addition.

The highest Vickers microhardness in the range of about $15 \mathrm{GPa}$ was found for lower loads $(10 \mathrm{~N})$. A slight increase in average microhardness have been obtained from composites prepared by volume combustion reaction exhibited highest hardness of about $6.50 \mathrm{GPa}$ was found for higher loads $(500 \mathrm{~N})$ at higher Fe addition. $40 \mathrm{wt} \%$.

The relevant data were listed in Table 2. In Fig. 10, a linear regression analysis was applied to the relations of $\mathrm{P}$ and $\mathrm{c}^{3 / 2}$ by the least square method.

As a result, the calculated slope A and intercept B were 0.0627 and 1.2736, respectively. The indentation fracture toughness was calculated to be $4.30 \mathrm{MPa} \mathrm{m}{ }^{1 / 2}$ for $40 \mathrm{wt} \%$ Fe addition ceramics matrix composite (CMCs) with excellent wear resistant will be confirmed.

The addition of Fe plays an important role in sintering additive (the ductility) in the propagation of filler in this nanocomposite and thus enhance the fracture toughness in comparison with his higher hardness. In addition, a high determination coefficient $\left(\mathrm{R}^{2}\right)$ of 0.9764 was obtained through the linear regression model [42]. IF (indentation fracture) was shown to be an effective method in the evaluation of fracture toughness for its convenience and material saving.

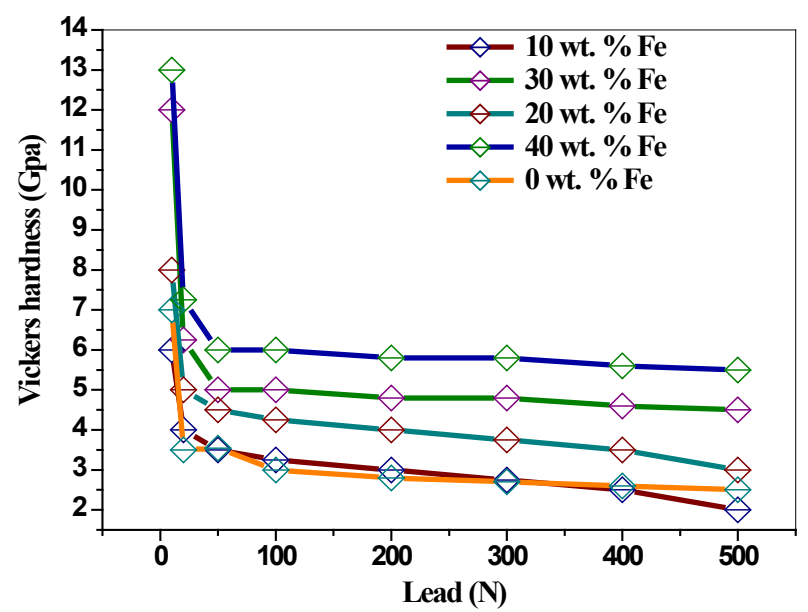

Figure 9. Representation the variation of Vickers microhardness fonction of the indentation leads of the sintered samples using a $20-\mathrm{mm}$

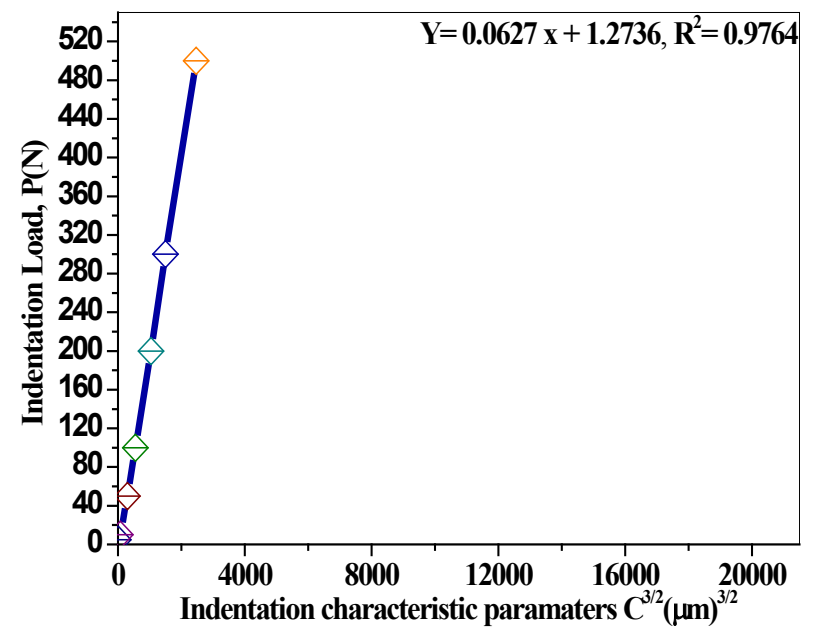

Figure 10. Correlation in between the applied load $P$ and half-length of median crack $\mathbf{c}^{3 / 2}$ of polished and etched surface for the sintered samples using the (IF) method.

Table 2. Data of Vickers indentation cracks and fracture toughness $\left(\mathrm{K}_{\mathrm{IC}}\right)$

\begin{tabular}{|c|c|c|c|c|c|c|}
\hline Sintered samples & $\begin{array}{l}\text { Half-length of } \\
\text { indentation } \\
\text { diagonal } \mathrm{a}(\mu \mathrm{m})\end{array}$ & $1_{(\mu \mathrm{m})}$ & $\begin{array}{l}\text { Half-length of } \\
\text { median crack } \\
\mathrm{c}(\mu \mathrm{m})\end{array}$ & $\begin{array}{l}\text { Indentation } \\
\text { parameter } \mathrm{c}^{3 / 2} \\
(\mu \mathrm{m})^{3 / 2}\end{array}$ & $\begin{array}{c}\mathrm{K}_{\mathrm{IC}} \\
\left(\mathrm{Gpa} \mathrm{m}^{1 / 2}\right)\end{array}$ & $\begin{array}{c}\mathrm{HV} \\
(\mathrm{GPa})\end{array}$ \\
\hline $\begin{array}{c}20 \text { wt. \% Fe } \\
\mathrm{P}=500 \mathrm{~N}, \mathrm{Hv}_{50} \\
\mathrm{P}=300 \mathrm{~N}, \mathrm{Hv}_{30}\end{array}$ & $\begin{array}{l}152.2 \\
170.1\end{array}$ & $\begin{array}{l}467.8 \\
450.3\end{array}$ & $\begin{array}{c}500 \\
352.3\end{array}$ & $\begin{array}{c}122309.74 \\
58007.62\end{array}$ & $\begin{array}{l}4.55 \\
4.59\end{array}$ & $\begin{array}{l}3.98 \\
4.10\end{array}$ \\
\hline $\begin{array}{c}40 \text { wt. \% Fe } \\
\mathrm{P}=500 \mathrm{~N}, \mathrm{Hv}_{50} \\
\mathrm{P}=300 \mathrm{~N}, \mathrm{Hv}_{30}\end{array}$ & $\begin{array}{c}95.1 \\
90.23 .5\end{array}$ & $\begin{array}{l}227 \\
324\end{array}$ & $\begin{array}{l}191.1 \\
356.5\end{array}$ & $\begin{array}{c}1243019.54 \\
59107.62\end{array}$ & $\begin{array}{l}4.70 \\
4.90\end{array}$ & $\begin{array}{l}5.50 \\
6.12\end{array}$ \\
\hline $\begin{array}{c}\text { 0 wt. \% Fe } \\
\mathrm{P}=500 \mathrm{~N}, \mathrm{Hv}_{50} \\
\mathrm{P}=300 \mathrm{~N}, \mathrm{Hv}_{30}\end{array}$ & $\begin{array}{c}73.2 \\
85.29\end{array}$ & $\begin{array}{l}157.7 \\
146.3\end{array}$ & $\begin{array}{l}220.9 \\
165.6\end{array}$ & $\begin{array}{c}152309.66 \\
60009.97\end{array}$ & $\begin{array}{l}3.65 \\
3.75\end{array}$ & $\begin{array}{l}3.00 \\
3.50\end{array}$ \\
\hline
\end{tabular}




\section{Conclusions}

In the present research, several quantities of $\mathrm{Fe}$ were added to the ETER-VC reaction of the $\mathrm{TiO}_{2}-\mathrm{Al}-\mathrm{C}$ system to $\mathrm{TiC}-\mathrm{Al}_{2} \mathrm{O}_{3}-\mathrm{Fe}_{3} \mathrm{Al}$ high performance composite ceramic matrix. The main results can be summarized as follows:

(1) Thermodynamic calculations predict that if the amount of $\mathrm{Fe}$ is lower than $53.13 \mathrm{wt} \%$, the reaction ignition and volume combustion mode processed and this allowed us to control the reaction up to $40 \%$ of iron addition.

(2) Phase analysis using XRD and Raman spectroscopy indicated that $\mathrm{Fe}_{3} \mathrm{Al}, \mathrm{Ti}(\mathrm{C}, \mathrm{O})$ and $\mathrm{Al}_{2} \mathrm{O}_{3}$ with some residual un-reacted carbon were the main products of the synthesis in the samples containing wt \% Fe. These products were not the same as those expected earlier.

(3) Using Raman spectroscopy analysis, it was demonstrated that all the carbon did not react with $\mathrm{Ti}$ in the sample containing no $\mathrm{Fe}$ and therefore the $\mathrm{C} / \mathrm{Ti}$ ratio in the $\mathrm{TiC}$ phase was less than unity. This led to a lower lattice parameter for the synthesized $\mathrm{TiC}$ in comparison to stoichiometric one. Also, the lattice parameter of $\mathrm{Ti}(\mathrm{C}, \mathrm{O})$ phase was lower in the samples containing higher Fe, likely as a result of dissolution of higher oxygen in this phase. This result is in agreement with XRD investigations.

(4) Microstructural observations by FESEM showed that additions of $\mathrm{Fe}$ changed the growth controlling mechanism of TiC particles.

(5) The adiabatic temperatures computed using the thermodynamic data of the new products function of 10 to $40 \mathrm{wt} \% \mathrm{Fe}$ content are in agreement with the Merzhanov criterion.

\section{Acknowledgements}

This project is funded by the Algerian ministry of education and scientific research (MESRS-Alger).

We are grateful to Aurélien Lepeutrec and Ibrahim Itaalit (LUSAC, EA 4253, Université de Caen Basse-Normandie (UCBN), Cherbourg-Octeville, France) for the helps in the FESEM and XRD investigation.

\section{Conflict of Interest}

The authors declare that is no Conflict of interest.

\section{REFERENCES}

[1] Zhu H, Dong K, Wang H, Huang J, Li J, Xie Z. Reaction mechanisms of the TiC-Fe composite fabricated by exothermic dispersion from $\mathrm{Fe}-\mathrm{Ti}-\mathrm{C}$ element system.
Powder Technol 2013; 246:456-61.

[2] Wang XH, Zhang M, Zou ZD, Song SL, Han F, Qu SY. In situ production of $\mathrm{Fe}-\mathrm{TiC}$ surface composite coatings by tungsten-inert gas heat source. Surf Coat Technol 2006;200:6117-22.

[3] Razavi M, Rajabi-Zamani AH, Rahimipour MR, Kaboli R, Ostad Shabani M, YazdaniRad R. Synthesis of Fe-TiC- $\mathrm{Al}_{2} \mathrm{O}_{3}$ hybrid nanocomposite via carbothermal reduction enhanced by mechanical activation. Ceram Int 2011;37:443-9.

[4] Zhang W, Zhang X, Wang J, Hong C. Effect of Fe on the phases and microstructure of TiC-Fe cermets by combustion synthesis/quasi-isostatic pressing. Mater Sci Eng A 2004;381:92 4 .

[5] Fatemi Nayeri SHR, Vahdati Khaki J, Aboutalebi MR. Implementation of combined mechanical activation and thermal analysis for identification of combustion synthesis mechanism in TiO2-Al-C system. Iran J Mater Sci Eng 2009-10;6:7-14.

[6] Fatemi Nayeri SHR, Vahdati Khaki J, Aboutalebi MR. The effect of milling conditions on the mechanical alloying and combustion synthesis of TiO2-Al-C powdermixture. Iran J Mater Sci Eng 2006;3:25-31. M. Sharifitabar et al. / Int. Journal of Refractory Metals and Hard Materials 47 (2014) 93-101

[7] Zou B, Xu J, Wang Y, Zhao S, Fan X, Hui Y, et al. Self-propagating high-temperature synthesis of TiC-TiB2-based Co cermets from a Co-Ti-B4C system and fabrication of coatings using the cermet powders. Chem Eng J 2013;233:138-48

[8] Moore JJ, Feng HJ. Combustion synthesis of advanced materials: part I. Reaction parameters. Prog Mater Sci 1995;39:243-73.

[9] Lee JH, Ko SK, Won CW. Combustion characteristics of TiO2-Al-C system. Mater Res Bull 2001;36:1157-67.

[10] Amel-Farzad H, Vahdati-Khaki J, Haerian A, Youssefi A. Combustion wave stability in diluted $\mathrm{TiO} 2 / \mathrm{Al} / \mathrm{C}$ system in atmospheric air. Solid State Sci 2008;10:1958-69.

[11] Xia TD, Munir ZA, Tang YL, Zhao WJ, Wang TM. Structure formation in the combustion synthesis of $\mathrm{Al}_{2} \mathrm{O}_{3}$-TiC composites. J Am Ceram Soc 2000;83:507-12.

[12] Bowen CR, Derby B. The formation of $\mathrm{TiC}-\mathrm{Al}_{2} \mathrm{O}_{3}$ microstructures by a selfpropagating high-temperature synthesis reaction. J Mater Sci 1996;31:3791-803.

[13] Choi Y, Rhee SW. Reaction of TiO2-Al-C in the combustion of TiC- $\mathrm{Al}_{2} \mathrm{O}_{3}$ composite. J. Am Ceram Soc 1995;78:986-92.

[14] Saidi A, Chrysanthou A, Wood JV, Kellie JLF. Characteristics of the combustion synthesis of $\mathrm{TiC}$ and Fe-TiC composites. J. Mater Sci 1994;29:4993-8.

[15] Saidi A, Chrysanthou A, Wood JV, Kellie JLF. Preparation of Fe-TiC composites by the thermal-explosion mode of combustion synthesis. Ceram Int 1997;23:185-9.

[16] Cho CH, Kim DK. Microstructure evolution and isothermal compaction in TiO2-Al-C combustion reaction. J Mater Synth Process 2002;10:127-34. 
[17] Xia TD, Liu TZ, Zhao WJ, Ma BY, Wang TM. Self-propagating high-temperature synthesis of Al2O3-TiC-Al composites by aluminothermic reactions. J Mater Sci 2001;36:5581-4.

[18] Zhu H, Jiang Y, Yao Y, Song J, Li J, Xie Z. Reaction pathways, activation energies and mechanical properties of hybrid composites synthesized in-situ from Al-TiO2-C powder mixtures. Mater Chem Phys 2012;137:532-42.

[19] Khoshhal R, Soltanieh M, Boutorabi MA. Formation mechanism and synthesis of Fe-TiC-Al2O3 composite by ilmenite, aluminum and graphite. Int $\mathrm{J}$ Refract Met Hard Mater 2014;45:53-7.

[20] Chakraborty SP, Sharma IG, Suri AK, Bose DK. Studies on preparation, characterization and evaluation of properties of $\mathrm{Fe}_{3} \mathrm{Al}$-based intermetallic alloy of composition Fe-16Al-5.44Cr-1Nb-0.5C. J Mater Process Technol 2001;115:413-22.

[21] Desai PD. Thermodynamic properties of selected binary aluminum alloy systems. J Phys Chem Ref Data 1987;16:109-24.

[22] Kubashewski O, Alcock CB. Metallurgical thermochemistry. New York: Pergamon Press; 1979.

[23] Barin I. Thermochemical data of pure substances. 3rd ed. New York: VCH; 1995.

[24] Ma J, Yang J, Bi Q, Liu W. Preparation of an ultrafine-grained Fe-40Al intermetallic compound. Acta Metall Sin 2010;23:50-6.

[25] Sen W, Xu BQ, Yang B, Sun HY, Song JX, Wan HL, et al. Preparation of $\mathrm{TiC}$ powders by carbothermal reduction method in vacuum. Trans Nonferrous Met Soc China 2011;21:185-90.

[26] Hajalilou A, Hashim M, Nahavandi M, Ismail I. Mechanochemical carboaluminothermic reduction of rutile to produce $\mathrm{TiC}-\mathrm{Al}_{2} \mathrm{O}_{3}$ nanocomposite. Adv Powder Technol 2014;25:423-9.

[27] Storms EK. The refractory carbides. New York: Academic Press; 1967.

[28] Jiang B, Hou N, Huang S, Zhou G, Hou J, Cao Z, et al. Structural studies of $\mathrm{TiC} 1-\mathrm{xOx}$ solid solution by Rietveld refinement and first-principles calculations. J Solid State Chem 2013;204:18.

[29] Leng Y. Materials characterization. Singapore: John Wiley \& Sons; 2008.

[30] Klein MV, Holy JA, Williams WS. Raman scattering induced by carbon vacancies in TiCx. Phys Rev B 1978; $15: 1546-56$.

[31] Lohse BH, Calka A, Wexler D. Raman spectroscopy as a tool to study $\mathrm{TiC}$ formation during controlled ball milling. J Appl Phys 2005;97:114912-7.

[32] Cava S, Tebcherani SM, Souza IA, Pianaro SA, Paskocimas CA, Longo E, et al. Structural characterization of phase transition of $\mathrm{A} 12 \mathrm{O} 3$ nanopowders obtained by polymeric precursor method. Mater Chem Phys 2007;103:394-9.

[33] Choi HC, Jung YM, Kim SB. Size effects in the Raman spectra of TiO2 nanoparticles. Vib Spectrosc 2005;37:33-8.

[34] Hassan M, Rawat RS, Lee P, Hassan SM, Qayyum A, Ahmad R, et al. Synthesis of nanocrystalline multiphase titanium oxycarbide (TiCxOy) thin films by UNU/ICTP and NX2 plasma focus devices. Appl Phys A 2008;90:669-77.

[35] Chappé JM, Fernandes AC, Moura C, Alves E, Barradas NP, Martin N, et al. Analysis of multifunctional titanium oxycarbide films as a function of oxygen addition. Surf Coat Technol 2012;206:2525-34.

[36] Kirkpatrick RJ. Crystal growth from the melt: a review. Am Mineral 1975;60:798-804.

[37] Fredriksson H, Akerlind U. Solidification and crystallization processing in metals and alloys. United Kingdom: John Wiley \& Sons; 2012.

[38] Hilling WB, Turnbull D. Theory of crystal growth in pure undercooled liquids. J Phys Chem 1956; 24:914.

[39] Zarezadeh Mehrizi M, Saidi A, Shamanian M, Eslami HR. Combustion synthesis of Fe-Al-TiC composite powders and effect of Al content on its characteristics. Powder Metall 2011;54:400-3.

[40] Zou Z, Wu Y, Yin C, Li X. Preparation of Fe-Al intermetallic-TiC- $\mathrm{Al}_{2} \mathrm{O}_{3}$ ceramic composites from ilmenite by SHS. J Wuhan Univ Technol Mater Sci Ed 2007;22:7069

[41] B. Bendjemil, K. Zemmour, A. Gunth, A. Leonhardt, P. Langlois, and D. Vrel, "Study on the Synthesis and Structural Characterization of the Cermets $\mathrm{TiC} / \mathrm{Fe}$ by Self-Propagating-High-Temperature Synthesis and by Thermal Explosion" Inter. Journal of SHS, 2006; 15, 1:85.

[42] Jianjun Sha, Jian Li, Shouhao Wang, Zhaofu Zhang, Yongchang Wang, Jixiang Dai, Materials and Design 107 (2016) 520.

[43] Rietveld H. M, A profile refinement method for nuclear and magnetics structures. J. Appl. Cryst. 1969 2, 65-71. 